\title{
MOBILIÁRIOS INTERATIVOS QUE CONECTAM A SOCIEDADE E SUAS EMOÇÕES COM A CULTURA AMAZONENSE.
}

\author{
Interactive Furnitures that connect the society and its emotions with the amazonense \\ culture.
}

FREIRE, Rebecca dos Santos; Graduanda; Universidade Federal do Amazonas rebeccaepufi@hotmail.com

MÁXIMO, Fábio Henrique Dias; Mestre; Universidade Federal do Amazonas

fabiomaximo@ufam.edu.br

\section{Resumo}

A influência das formas no design emocional visa expandir os limites atuais do design de mobiliário e gerar produtos com maior interação com os usuários. Analisando pesquisas que avaliaram artefatos em sua interação visual e física, verificou-se que atrelar o valor cultural, social, humano e institucional aprofunda a relação emocional dos produtos e das pessoas, alterando seus conceitos e percepções de uso. A pesquisa buscou experimentar novas características morfológicas na configuração de mobiliários urbanos, empregando formas e símbolos culturais da região. Em face dos dados levantados na pesquisa e conforme o experimento realizado no campus universitário, com 22 alunos que testaram a intervenção realizada em um mobiliário urbano, conclui-se que o mobiliário implantado agradou os usuários e alcançou seu objetivo parcial, uma vez que os campos emocionais caracterizados como emoções negativas na avaliação do produto, foram os menos demonstrados pelos usuários.

Palavras Chave: Cultura, Design Emocional, Interação e Mobiliário Urbano.

\begin{abstract}
The influence of forms on emotional design aims to expand the current boundaries of furniture design and generate products with greater interaction with users. Analyzing researches that evaluated artifacts in their visual and physical interaction, it was found that linking cultural, social, human and institutional values deepens the emotional relationship between products and people, changing their concepts and perceptions of use. The research sought to experiment new morphological characteristics in the configuration of urban furniture, employing cultural forms and symbols of the region. Considering the data collected in the research and according to the experiment carried out at the university campus, with 22 students who tested the intervention performed in an urban furniture, it is concluded that the furniture implanted connected with the users and reached its partial objective, since the emotional fields characterized as negative emotions in the evaluation of the product, were the least demonstrated by the users.
\end{abstract}

Keywords: Culture, Emotional Design, Interaction and Urban Furniture. 


\section{Introdução}

Entender a cultura, sua importância e seus reflexos na sociedade é primordial, uma vez que as relações culturais entre homem e cidade podem ser defendidas com base nos seus costumes e fatos históricos; afinal a sociedade atual é resultado de três momentos temporais: das ações passadas; de suas ações no presente e; os impactos dessas atitudes no futuro. Também é percebido que a cidade, atua como uma manifestação física da sociedade, ao refletir seu modo de viver e de se relacionar.

Por manifestar os costumes de um povo, a cidade torna-se um organismo vivo, uma extensão dos habitantes de uma localidade. Assim, os mobiliários urbanos, além de atender a requisitos formais e estéticos, devem acima de tudo, representar uma sociedade e ir além: possibilitar que os indivíduos de um determinado local se conectem através dos elementos urbanos presentes.

No que diz respeito à percepção do ambiente urbano, percebe-se que os habitantes manauaras não estão ligados intimamente com a cultura local no que diz respeito a espaços públicos. Entretanto, apesar da ausência de afeição cultural, a população idealiza no seu imaginário uma cidade que apresente suas heranças históricas e ao mesmo tempo acompanhe o crescimento urbano da cidade de forma eficaz.

Ao examinarmos ambientes comunitários amplos, como as universidades, podemos considerar que neste ecossistema ocorre o mesmo fenômeno, pois todos os dias, mais de 10.000 alunos transitam pelo Campus Universitário, e se utilizam dos mobiliários urbanos presentes implementados por construtoras que os produzem em concreto armado pela facilidade de produção e baixo custo. Contudo, estes mobiliários são evidentemente desconfortáveis e sem apelo visual, não havendo nenhum cuidado estético e funcional que de fato auxilie o usuário nas atividades diárias de trabalho e lazer.

Ao abordarmos o conceito de Design Emocional, verifica-se que em cada produto existe um apelo emocional que vai se conectar com o usuário e criar uma relação, sendo esta a chave para a compra do produto; tal afirmação se refere ao Design Emocional do produto, este precisando atender aos seguintes critérios:

- Estética

- Usabilidade/ Compreensão

- Status Social/ Valor Simbólico

Considerando esses aspectos, percebe-se que não se poderia falar em design emocional de forma desvinculada da estética e/ou do significado simbólico e cultural; que nenhuma experiência seria caracterizável de forma desvinculada de uma ou de mais "adjetivações" por uma das três dimensões experienciais propostas por Hekkert (2006). Assim, a pesquisa propõe 'conectar' usuários ao mobiliário através da exploração dos conceitos culturais e sociais para construir uma relação emocional do produto com o usuário(estima), por meio de símbolos e representações, além de avaliar seus respectivos efeitos na configuração e na sua interação com o ambiente, dando uma história que também conecte o produto à sociedade. 


\section{Objetivos}

\subsection{Geral}

Empregar símbolos e formas culturais para a concepção de mobiliários amazônicos.

\subsection{Específicos}

- Identificar as relações entre as morfologias dos mobiliários e as percepções simbólicas dos usuários;

- Experimentar as características morfológicas interativas na configuração de mobiliários.

\section{Metodologia}

A pesquisa foi baseada em métodos e técnicas de design emocional e do concept design, mescladas dentro das metodologias de Munari e Bonsiepe. Adaptando os dois métodos, explorouse de maneira minuciosa a relação do Design Emocional na concepção de um mobiliário com seu conceito voltado para a cultura amazonense. Além disso, o projeto utilizou ferramentas e métodos do Design Emocional, tais como o Modelo de Análise do Design Emocional - MADE (Figura 1), com o propósito de auxiliar a compreensão e de certificar que determinadas emoções sejam, de fato, ser estimuladas.

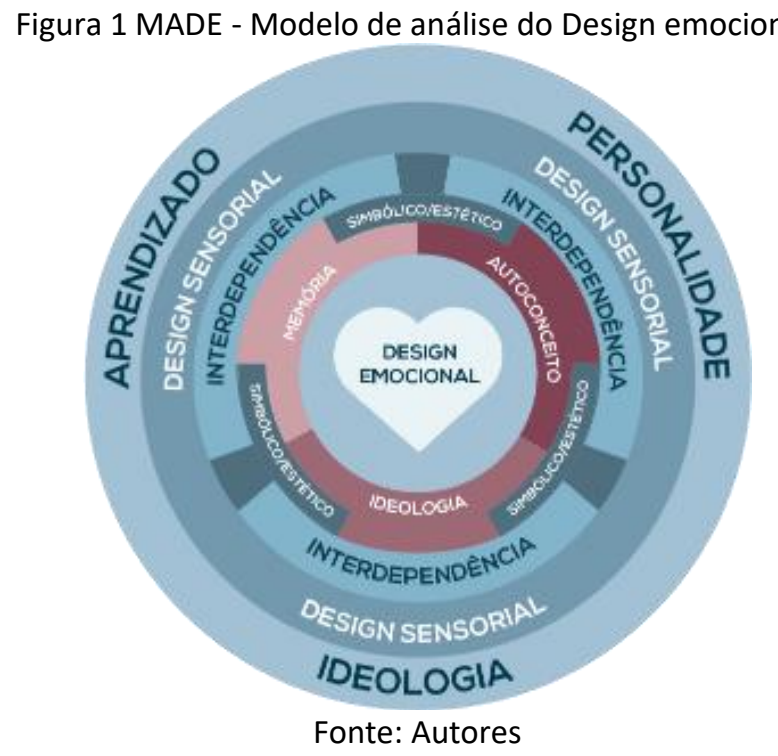

Quando se trata de métodos e procedimentos do projeto, Munari (2002) inicia com a definição do problema para assim definir seu objetivo, e em sequência divide o problema em partes para facilitar sua resolução e chegar à solução final. Em sua metodologia são abordadas 11 fases: problema, definição do problema, componentes do problema, coleta de dados, análise de dados, criatividade, materiais e tecnologia, experimentação, modelo, verificação e solução. 
Em outro aspecto, a metodologia de Bonsiepe (1983) fornece uma orientação para o processo projetual apresentando técnicas e métodos para o desenvolvimento de produtos, através de projetos experimentais. Ele defende que se deve ter uma liberdade relativa na seleção de alternativas para o projeto, podendo tomar decisões pessoais devido a sua competência profissional. Sendo assim, somente sugere as propostas por ele utilizadas, que poderão ser selecionadas para o desenvolvimento de outros novos produtos, aperfeiçoando o desempenho, descrevendo técnicas e processos de criação de produto a fim de resolver problemas existentes.

Para que a pesquisa seja feita de maneira objetiva, a coleta de informações foi baseada nos seguintes problemas-chave, solucionados ao longo do projeto:

- Qual a influência do Design Emocional na concepção de um mobiliário?

- As formas geométricas e orgânicas podem afetar as percepções sobre o produto?

- É possível gerar interação entre o usuário e o produto por meio do Design Emocional?

Com os problemas apresentados, pretendeu-se entender como configurar um mobiliário que por meio do Design Emocional, representasse a cultura amazonense e tivesse interação direta com o usuário, explorando o simbolismo de suas formas.

\section{Desenvolvimento}

Em um projeto de Design centrado no usuário é importante a realização de testes de usabilidade no decorrer do desenvolvimento do produto afim de identificar os problemas à serem resolvidos, gerar troca de experiência com os usuários, facilitar a decisão sobre alternativas importantes e tornar a avaliação dos protótipos à serem gerados mais efetiva. Por isso, visando mostrar ao usuário a mudança de um mobiliário comum ao seu dia-a-dia, optou-se por realizar uma intervenção em um mobiliário de concreto localizado no corredor do curso de Design na Faculdade de Tecnologia através da aplicação de um assento de madeira (FIGURA 2 e 3) constituído de cinco ripas, três barras chatas e parafusos cromados.

Figura 2 - Modelo virtual (à esq.) e vista explodida (à dir.) do banco para o experimento.

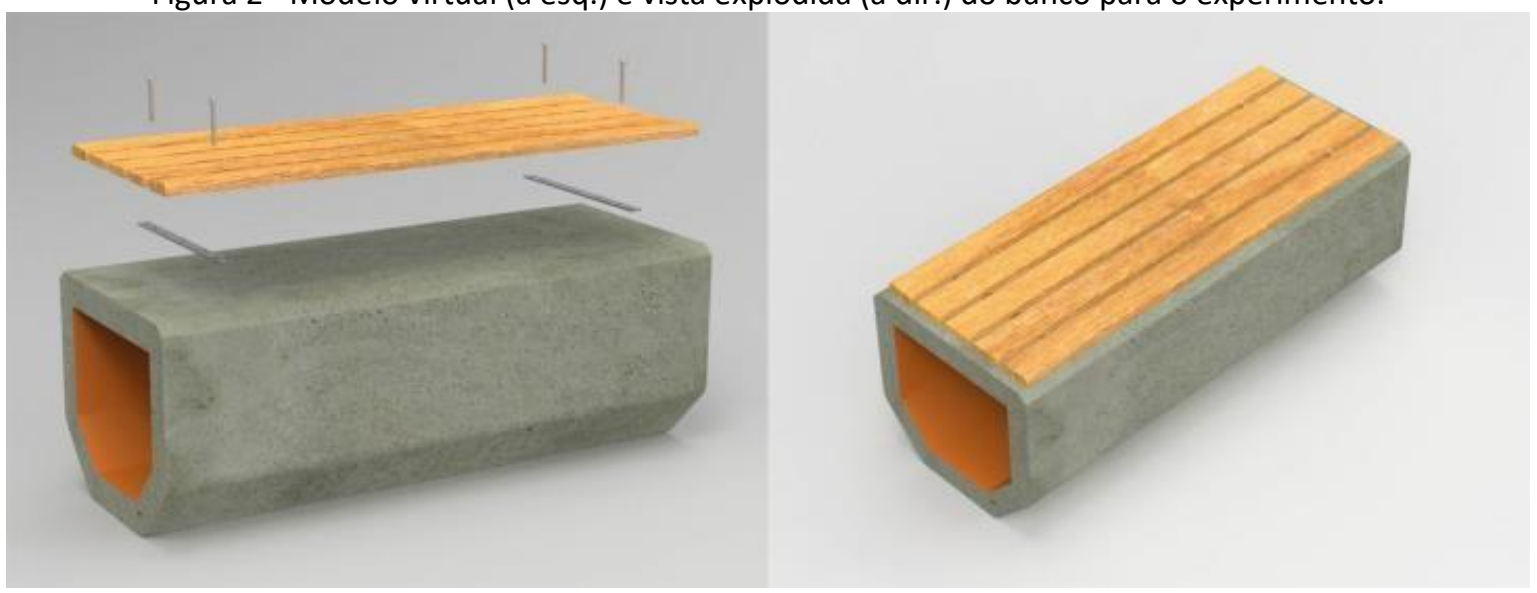

Fonte: Autores

13 Congresso Brasileiro de Pesquisa e Desenvolvimento em Design, Univille, Joinville (SC)

05 a 08 de novembro de 2018 
Figura 3-Implementação das ripas confeccionadas no Lab. Marcenaria e de Rep. Tridimensional.

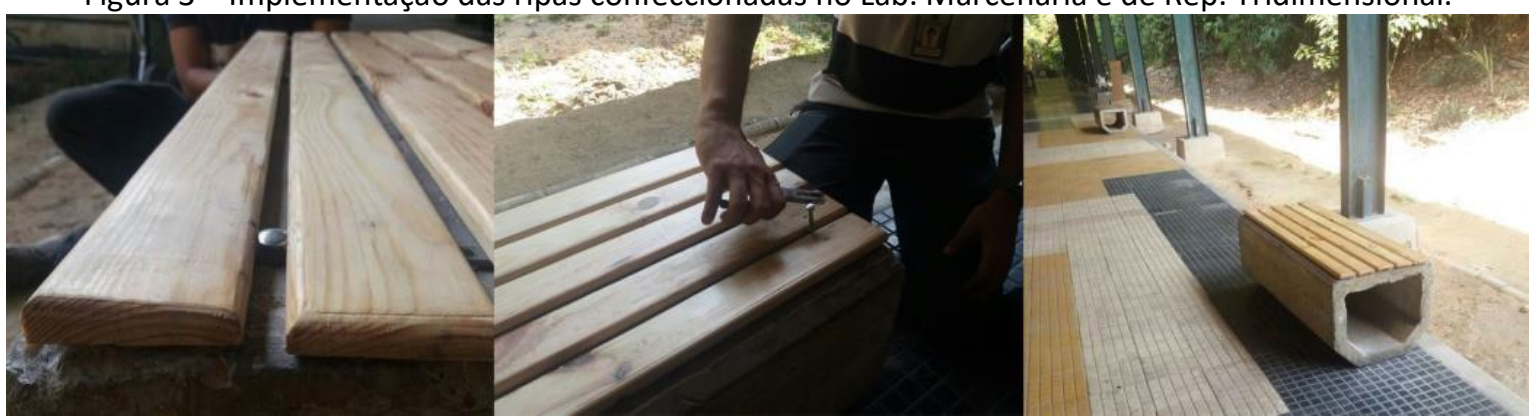

Fonte: Autores

O modelo de avaliação aplicada na primeira fase do projeto é caracterizado como Avaliação Formativa, que consiste em avaliar o produto no começo e durante o processo de desenvolvimento de tal, visando aperfeiçoar o produto final. Este modelo não se trata de experimentação controlada, com rigor estatístico, de testes de fatores humanos já que se deseja resultados mais rápidos, mas sim satisfazer as necessidades do usuário para se conseguir um alto grau de usabilidade. Sendo assim, a Avaliação Formativa endereça principalmente o caminho entre a prototipação e desenho/redesenho.

Para o teste de Usabilidade foi necessário buscar ferramentas dentro do campo do Design Emocional para entender a relação entre o usuário, o produto e o meio no qual este está inserido. Para esta pesquisa foi utilizado a ferramenta PrEmo, que instrui dois tipos de questionários: um sendo digital (no qual foram colocados os personagens animados com sons de auxílio) e outro físico (baseado em cards). Prontamente, decidiu-se iniciar o experimento aplicando o questionário físico para que houvesse contato com o usuário no ambiente de teste.

Esta ferramenta foi desenvolvida por Pieter Desmet (2007) e comercializada pela companhia Susa Group, que possibilita mensurar as emoções, através de animações e sons, despertadas por estímulos por meio da utilização de personagens animados, os quais são utilizados para descrever o que os usuários sentem através de uma escala até cinco baseada em uma ilustração; dessa forma é possível compreender que mais de uma emoção pode ser sentida ao mesmo tempo.

Os personagens animados do PrEmo foram desenvolvidos com base em 14 emoções, que se enquadram em 4 dimensões distintas:

- Emoções de contexto social: Orgulho, Admiração, Vergonha e Desprezo

- Emoções de contexto material: Desejo, Fascinação, Aversão e Tédio

- Emoções baseadas em expectativas: Esperança, Satisfação, Medo e Insatisfação

- Emoções de bem-estar geral: Alegria e Tristeza 
Figura 4 - Personagens desenvolvidos conforme as emoções e dimensões.

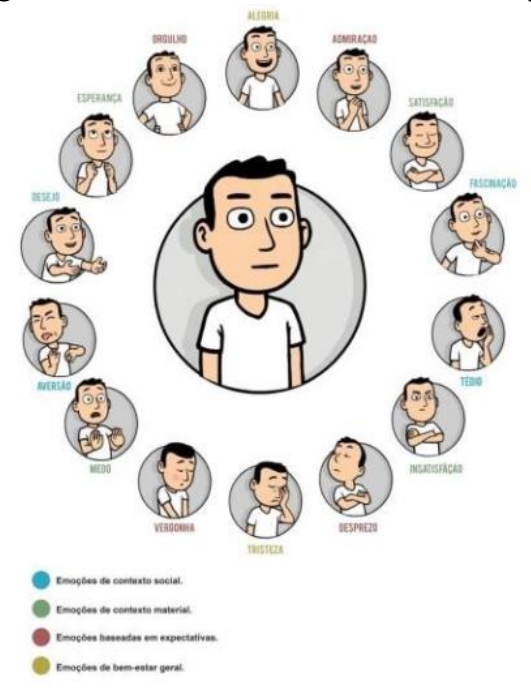

Fonte: Autores

Figura 5 - Cards desenvolvidos para o teste.

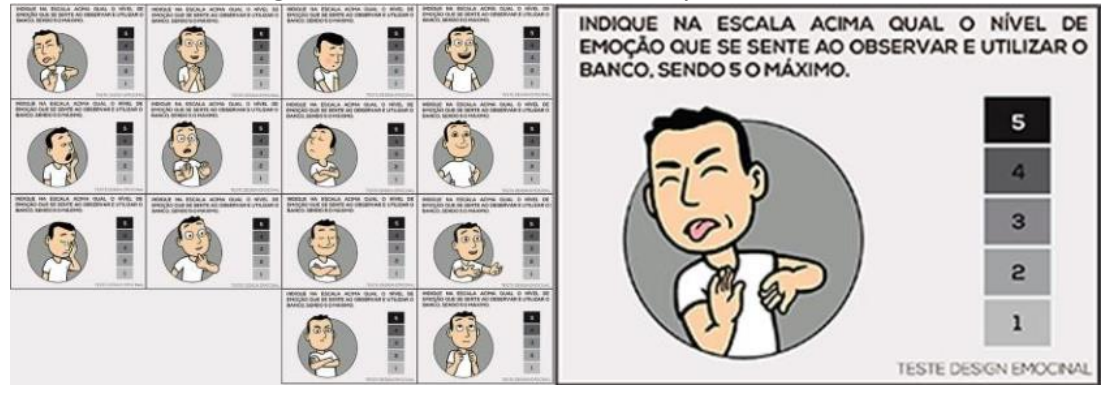

Fonte: Autores

Figura 6 - Card Inicial - Como você está se sentindo agora?

\section{COMO VOCÊ SE SENTE AGORA?}
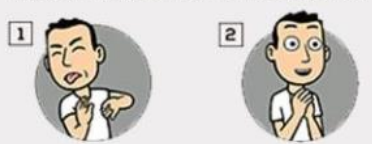

3
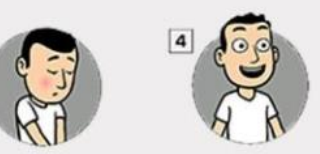

5

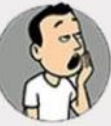

6 .

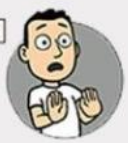

7

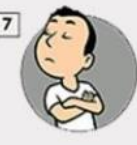

9

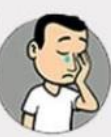

피

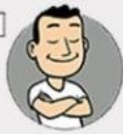

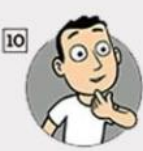
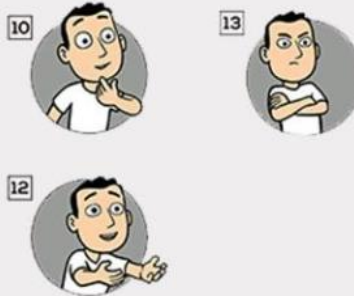

Fonte: Autores

O questionário foi realizado com 22 alunos da FT em dois momentos. No primeiro momento foi analisado o nível emocional momentâneo do usuário, com a finalidade de compreender como uma emoção pode afetar a percepção de um produto. 


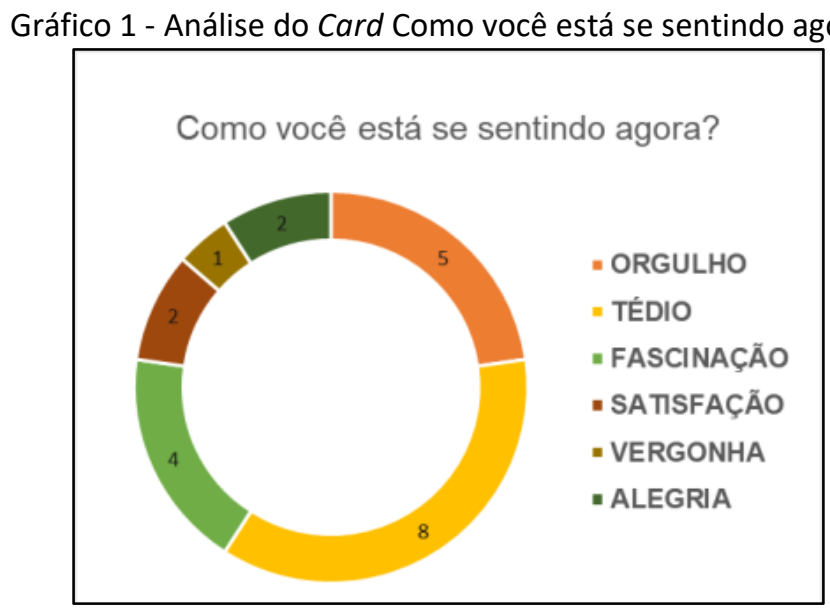

Fonte: Autores

Em seguida, houve uma análise ao OBSERVAR o mobiliário e ao UTILIZAR o mobiliário, visando compreender se o produto exposto alcança níveis estéticos e funcionais no momento de interação com o usuário e para melhor compreensão foi estabelecido dois gráficos, os quais compreendem respectivamente emoções positivas e negativas (Gráfico 2). Como o experimento foi realizado com 22 pessoas, o máximo de pontuação que cada CARD poderia receber era de 110, uma vez na qual cada CARD possui uma escala de 0-5 sendo 5 o maior nível da emoção selecionada.

Gráfico 2 - Análise das emoções positivas / Análise das emoções negativas ao observar e ao utilizar o mobiliário.
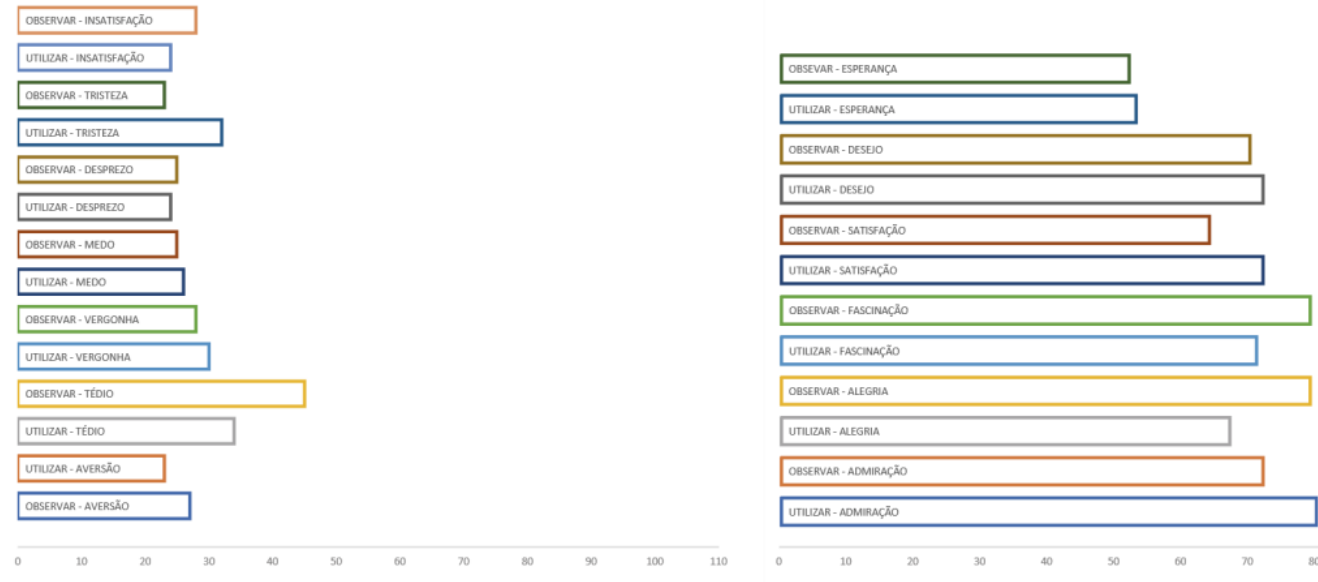

Fonte: Autores

Como resultado final, o mobiliário implantado teve maior impacto no campo funcional do que no visual, uma vez que as notas foram maiores no utilizar/sentar do produto. Dessa forma podemos entender que o objetivo de causar um impacto entre o usuário e o produto foi parcialmente alcançado, ainda possuindo déficits à serem corrigidos na próxima fase, como o caso da estética do produto e do conforto, contudo já é possível identificar o aumento da interação entre o usuário e o mobiliário.

13 Congresso Brasileiro de Pesquisa e Desenvolvimento em Design, Univille, Joinville (SC) 


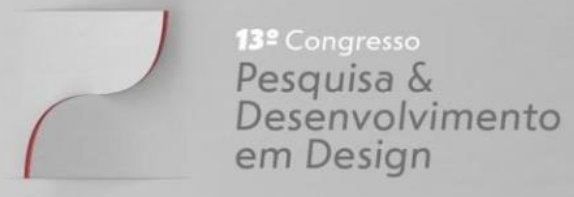

Artigo Completo

A partir desta primeira análise conclui-se que o mobiliário implantado agradou os usuários e alcançou seu objetivo parcial, uma vez que os campos emocionais: Aversão, Vergonha, Desprezo, Tristeza, Medo e Insatisfação, que se tratam de emoções negativas, foram os menos demonstrados na avaliação do produto pelos usuários.

Conforme as informações obtidas nas etapas de levantamento de dados, produção, questionário e análise, foram geradas alternativas conceituais e baseadas no Design Emocional com o intuito de na fase final do projeto, houvesse a implementação de um mobiliário interativo e cultural na Universidade Federal do Amazonas que alcance o usuário e seus campos emocionais de forma mais precisa e destacada do que da maneira do banco atual da faculdade, buscando assim atingir de uma forma mais consistente a relação entre o usuário e o produto.

\section{Repertório visual}

Em design de produtos, a análise de similares contemporâneos é conhecida como sincrônica e permite, segundo Gomes (2004), verificar o produto em seu contexto e relacioná-lo a outros semelhantes existentes no mercado. Analisar produtos já existentes e bem-sucedidos no âmbito do Design Emocional e de Design de Produto é importante no desenvolvimento desta pesquisa para que seja possível obter resultados exímios e de atingir o usuário de tal no fim do projeto, uma vez que, de acordo com Alina Wheeler (2008), "quando utilizada corretamente, produz resultados fantásticos". No desenvolvimento deste projeto foi formado um quadro com imagens de mobiliários urbanos que cumprem a função de interação com o público, acomodação confortável, ligação com o ambiente natural, conforto e apelo visual. Esta pesquisa servirá de base para a criação dos Painéis Semânticos do projeto, além de servir como um guia para o desenvolvimento do mobiliário final.
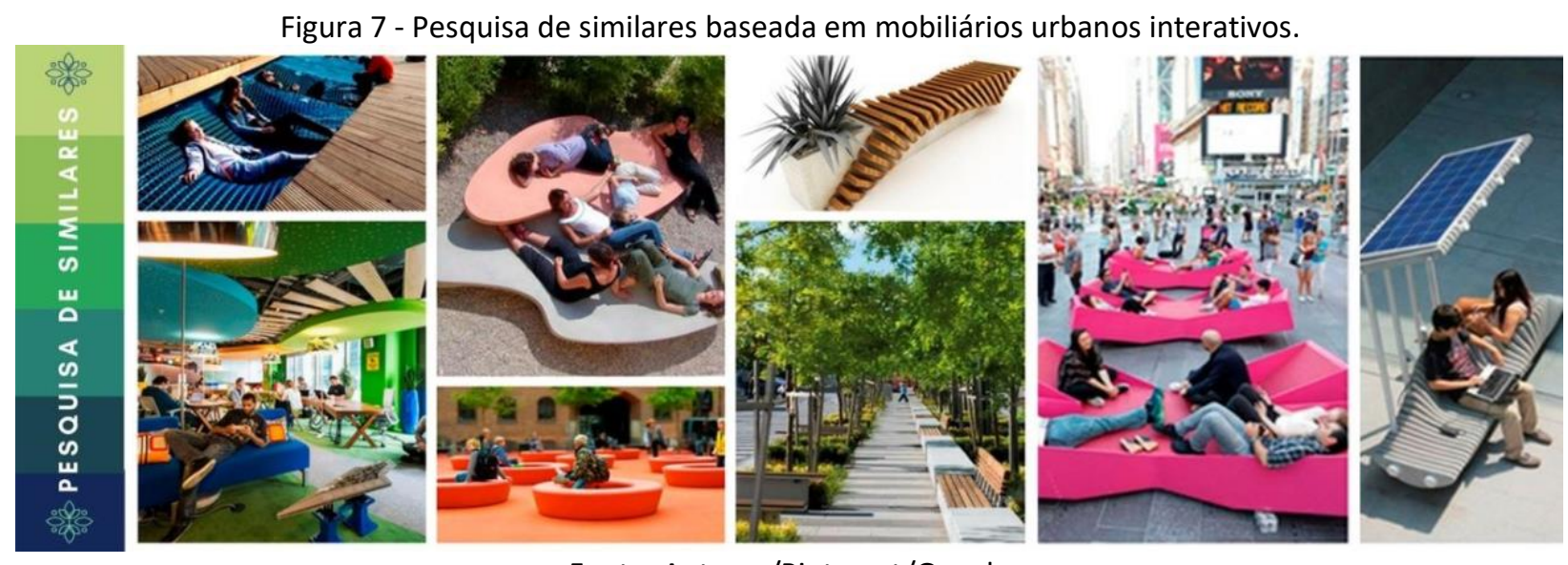

Fonte: Autores/Pinterest/Google

\section{Painel Semântico}

Na construção de um Projeto de produto o desafio é transformar conceitos abstratos em produtos concretos. A atividade criativa é facilitada por meio da utilização de ferramentas que auxiliam o processo de geração de ideias. Uma etapa importante, presente em grande parte das 
metodologias, é a definição do conceito que guiará o projeto; enquanto os painéis semânticos são aplicados para contribuir na construção do conceito do projeto nas fases iniciais.

Os painéis semânticos têm a função de integrar a comunicação visual com o objetivo de compreender o usuário e o produto à ser criado. Baxter apresenta uma divisão dos painéis de imagens em etapas que acompanham o desenvolvimento projetual: o "painel de estilo de vida" que demonstra o perfil do público consumidor; o "painel da expressão do produto" que propõe expressar as emoções e valores que se pretende atribuir ao produto; e o "painel do tema visual" que se refere ao conceito expresso através de imagens que remetem aos estilos visuais que serão utilizados no desenvolvimento do produto.

1. Painel de Estilo de Vida: Este vem a explicar quem é o usuário e seus interesses.

Usuário: Jovens e Adultos estudantes, professores e servidores que costumam acordar cedo e se locomover de ônibus até a Universidade Federal do Amazonas; estão em constante locomoção dentro do Campus ao saírem de uma sala para outra para assistirem aulas/palestras; costumam realizar trabalhos em equipes e raramente se encontram sozinhos por dentro da Instituição e costumam possuir uma vida noturna ativa.

Figura 7 - Painel Semântico 01

PAINEL DE ESTILO DE VIDA

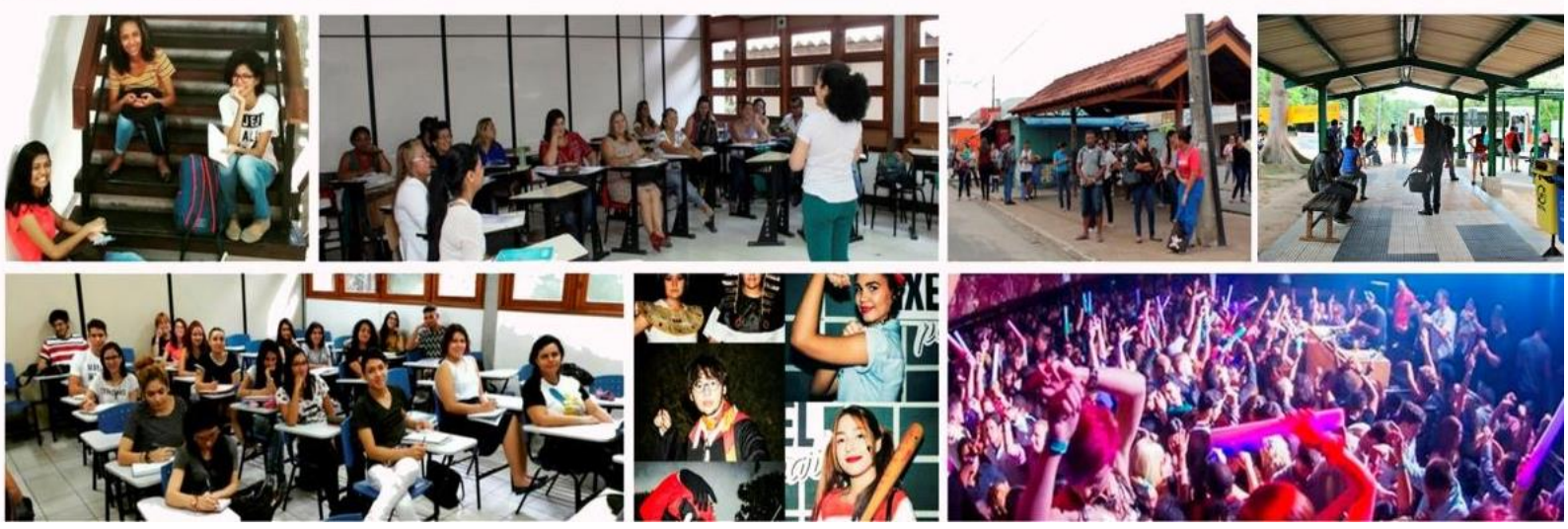

Fonte: Autores/Pinterest/Google

2. Painel da Expressão do Produto: Este vem a explicar conceitos do produto à ser desenvolvido através de imagens simbólicas.

Produto: Deve ser confortável, trazer tranquilidade e calma; deve retratar a cultura do local, podendo se inspirar na flora, fauna ou em materiais regionais; deve ser inovador e trazer um novo olhar do usuário; deve promover a interação de usuários sendo assim um produto à ser utilizado por um coletivo e não por um individual; deve ter apelo visual e atratividade. 
PAINEL DA EXPRESSÃO DO PRODUTO

Figura 9 - Painel Semântico 02
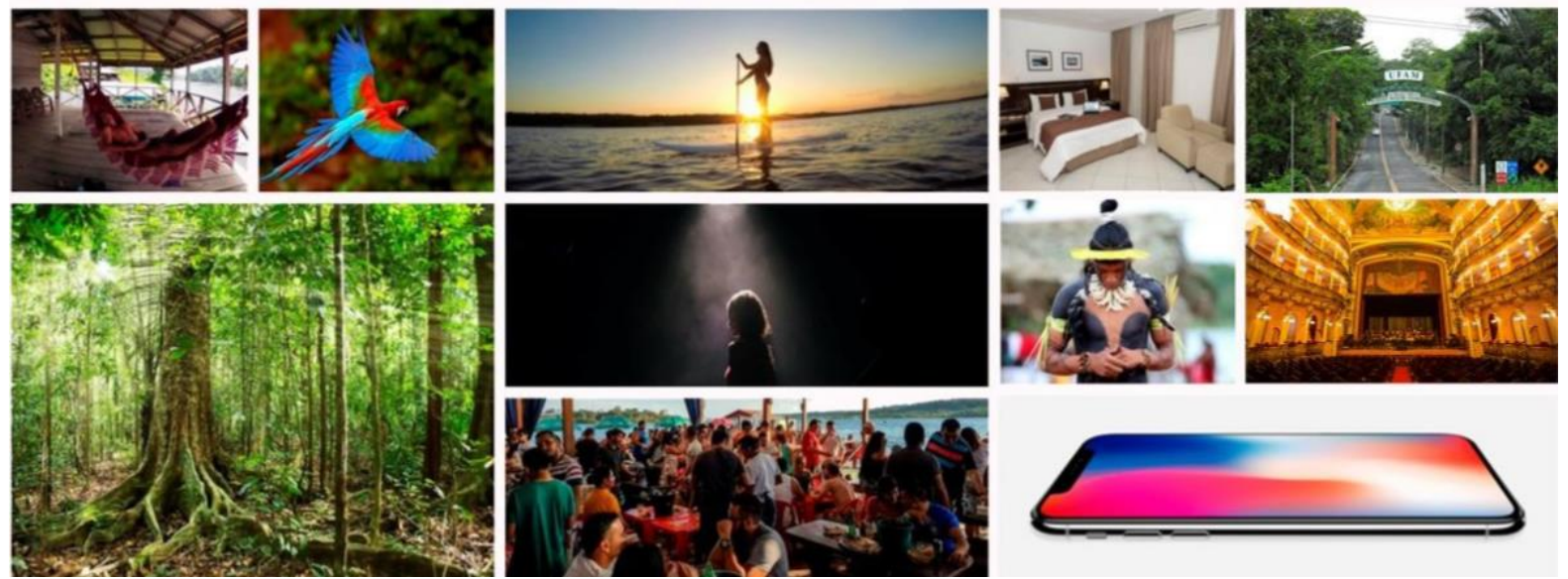

Fonte: Autores/Pinterest/Google

3. Painel de Tema Visual: Este vem a expor produtos já existentes que representam os conceitos previamente estabelecidos no Painel da Expressão do Produto. Tais produtos não precisam estar na mesma classificação do produto à ser desenvolvido neste projeto.

Conceitos à serem explicados por meio de produtos já existentes: Conforto, Tranquilidade, Cultura, Interação e Apelo Visual.

Figura 10 - Painel Semântico 03

PAINEL DE TEMA VISUAL

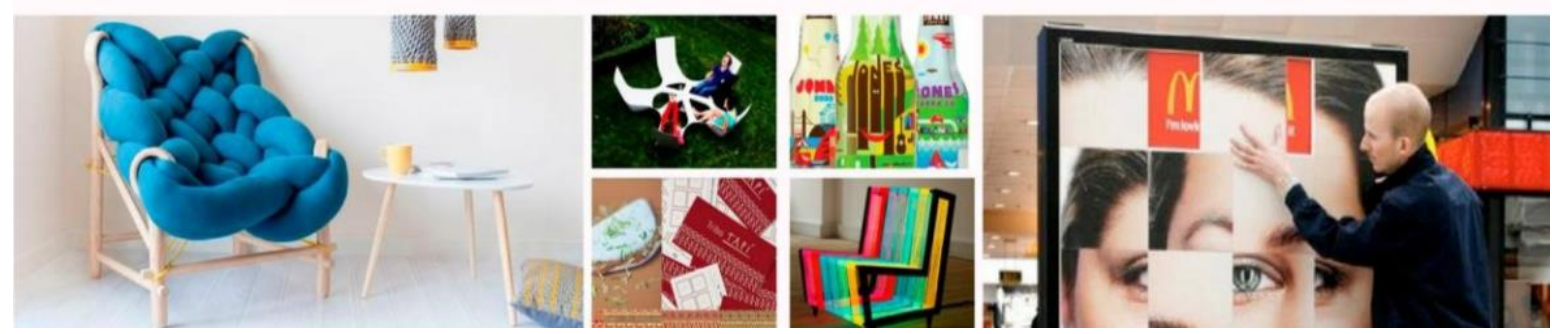

Fonte: Autores/Pinterest/Google

\section{Geração de Alternativas}

O Problema identificado neste projeto foi o de criar um novo mobiliário urbano à ser implantado na Universidade Federal do Amazonas, devendo trazer em seu conceito a cultura do estado e o apelo emocional ao usuário, estabelecendo assim uma relação entre o indivíduo e o produto. Para isso foi preciso analisar e organizar os dados já obtidos na Coleta e Análise de dados, para geração de um Check-List, a seguir, que serviu como diretriz para geração de alternativas.

- Mobiliário atrativo (estética), confortável, resistente à fatores intempéries (umidade, calor), suportar o peso mínimo de 3 pessoas;

- Deve transmitir conforto, interesse, satisfação, tranquilidade, cultura, incentivo, descanso;

13o Congresso Brasileiro de Pesquisa e Desenvolvimento em Design, Univille, Joinville (SC) 
- Deve tornar o ambiente mais atrativo, trazer aspectos da flora do local para o mobiliário e respectivamente para o usuário, retratando assim a cultura do Estado;

- Material acessível e de fácil processo de fabricação;

- Considerar o usuário: Alunos, servidores públicos e professores entre 17-50 anos, que estão constantemente em movimento pelo Campus e que na hora de 12:00 - 14:00 precisam descansar e se sentir bem;

- Considerar o ambiente (Universidade Federal do Amazonas): Possui muita flora, áreas recreativas sem mobiliários, e poucos lugares adequados para descanso na hora de 12:00 14:00.

Após a definição dos itens necessários para a conceituação do novo mobiliário urbano à ser aplicado na UFAM, inicia-se o processo de geração de alternativas do projeto que explorou a potencialidade criativa na produção de conceitos visuais do produto.

Logo, foi determinado a utilização do método de Concept Design que geralmente é entendido como um output intermediário do processo criativo e, mais especificamente, é considerado como uma ideia projetual ainda em estado inicial. Neste processo são gerados diversos esboços de novas ideias visando atender os requisitos antes selecionados, e tais esboços possuem um grande valor no processo criativo pois se tratam das soluções para resolver o problema projetual proposto.

\section{Resultados}

Buscando retratar símbolos e formas culturais da região (Figura 11), o projeto baseou-se no formato dos rios e das cachoeiras, ao utilizar suas formas sinuosas e suas curvas em um âmbito geométrico ao propor características modernas e inovadoras, além de explorar em seus detalhes e em suas linhas conceituais, os ideogramas e símbolos indígenas buscando trazer aspectos estéticos atrativos e agradáveis.

Figura 11 - Elementos culturais inspiradores para a geração de Concepts.

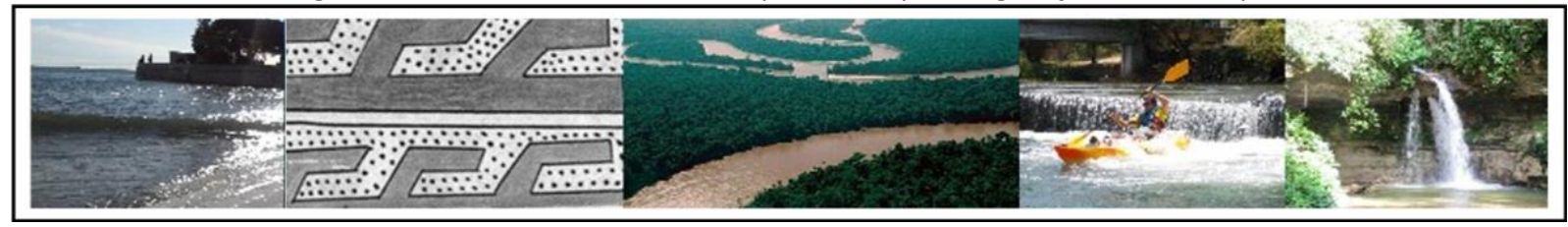

Fonte: Google

Foram elaborados 29 concepts, dos quais em uma seleção prévia foram reduzidos a 18 propostas que serão avaliadas novamente por meios dos cards emocionais de Desmet; sendo tais concepts separados em 6 grupos:

- Grupo 01 - Simplicidade e Diversidade: Projetado visando desenvolver um banco que não fosse de difícil fabricação e que causasse um impacto visual no display de seus assentos. É possível observar (Fig.12) três alternativas desenvolvidas, tendo a primeira o conceito

13o Congresso Brasileiro de Pesquisa e Desenvolvimento em Design, Univille, Joinville (SC) 
voltado para formas geométricas, possuindo encosto leve para a coluna, e uma área aberta para colocar objetos em sua parte inferior; a segunda utiliza formas mais orgânicas, possuindo um "vazado" em seu assento com o objetivo de atratividade visual; já a terceira é composta por formas mais geométricas e por possuir um "vazado" em seu assento, criando uma harmonia visual e separando suas áreas para a ocupação dos usuários.

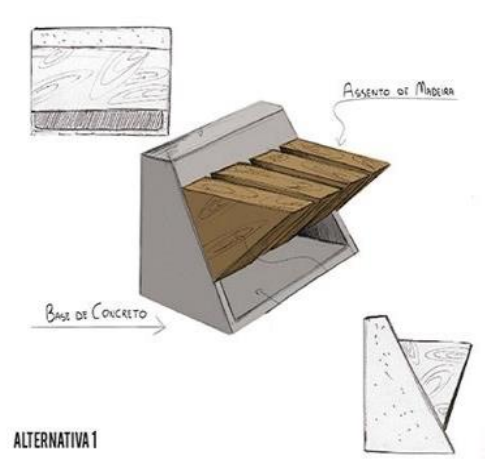

ALTERNATIVA 1

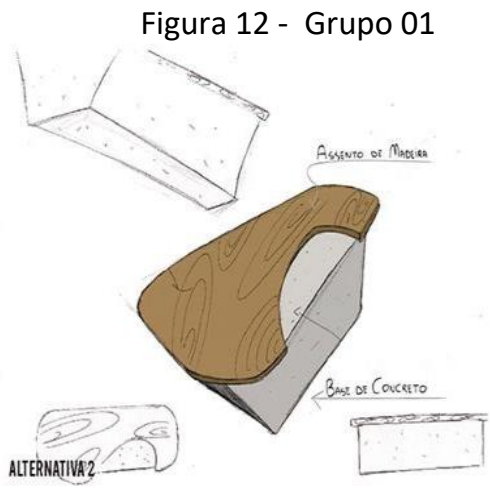

Fonte: Autores

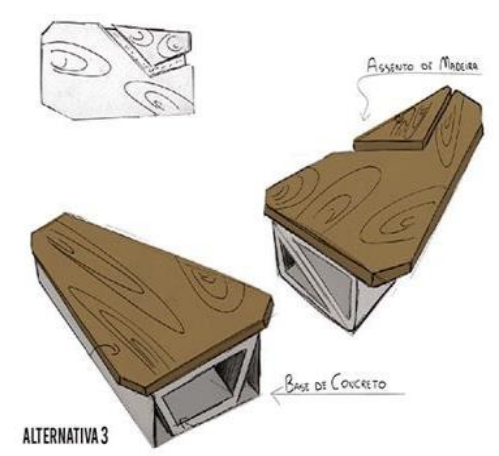

- Grupo 02 - Forma e Material: Projetado com o objetivo de explorar as formas e o impacto visual visando mobiliários de concreto, em sua maior parte. Na Fig. 13 é possível encontrar os concepts, possuindo o no 4 forma orgânica e impacto visual em sua estrutura equilibrada e área para plantas gerando um contato harmonioso com a natureza, além de possuir um assento modular que traz um aspecto estético atrativo; a quinta geração explora a forma sinuosa, além de possuir duas áreas para o estacionamento de bicicletas em sua lateral e assento simples de madeira; por fim a alternativa 6 é composto por várias camadas, tendo aspecto visual atrativo e simples.

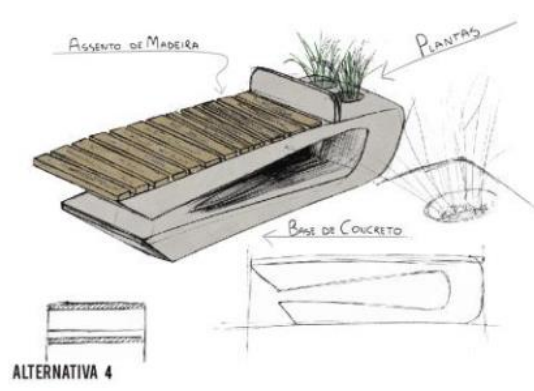

Figura 13 - Grupo 02

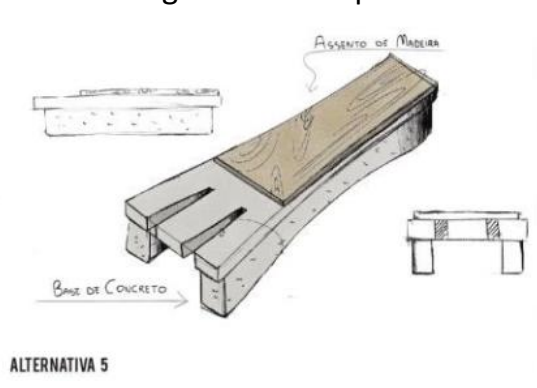

Fonte: Autores

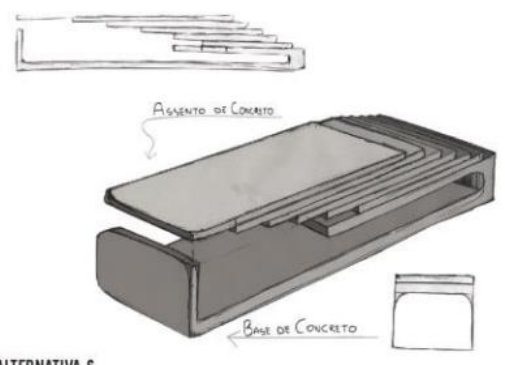

ALTERNATIVA 6

- Grupo 03 - Conforto: Buscou desenvolver um mobiliário com encosto e impacto visual, ao desenvolver (Fig.14) por meio de formas geométricas, um banco que possui encosto modular e maleável, se adaptando ao usuário. 


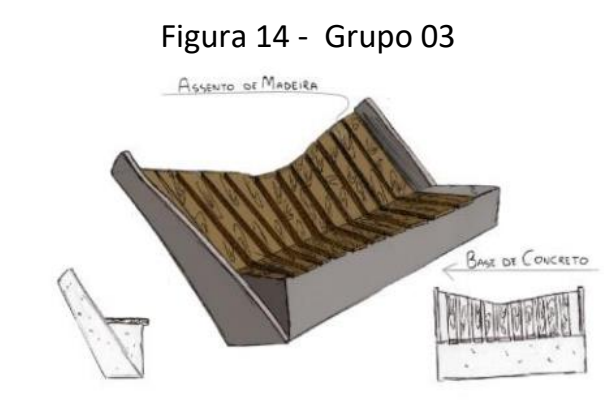

ALTERNATIVA 7

Fonte: Autores

- Grupo 04 - Divisão e Modularidade: Desenvolvidos com o intuito de poderem ser replicados e espalhados na área de convivência da universidade. Na Fig. 15 estão dispostas quatro

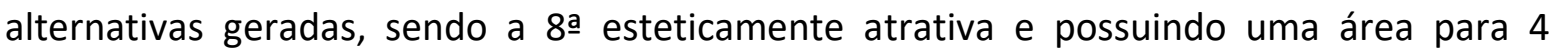
usuários; o concept $\mathrm{n}$ o 9 se trata de um banco individual, vazado nas laterais, atrativo e modular; o no 10 utiliza formas geométricas de uma maneira atrativa, possuindo declive para descanso dos pés e áreas separadas para os usuários; e o № 11 é um mobiliário simples, atrativo e com áreas separadas para os usuários.

Figura 15 - Grupo 04

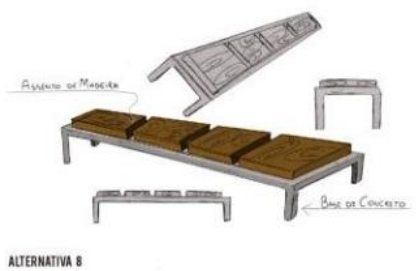

AUERNATIVA 8

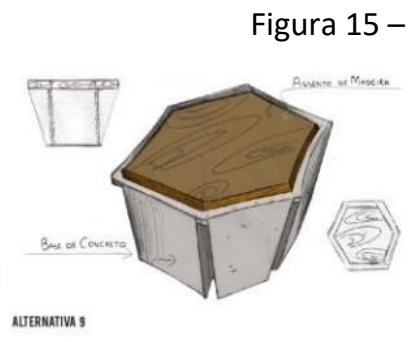

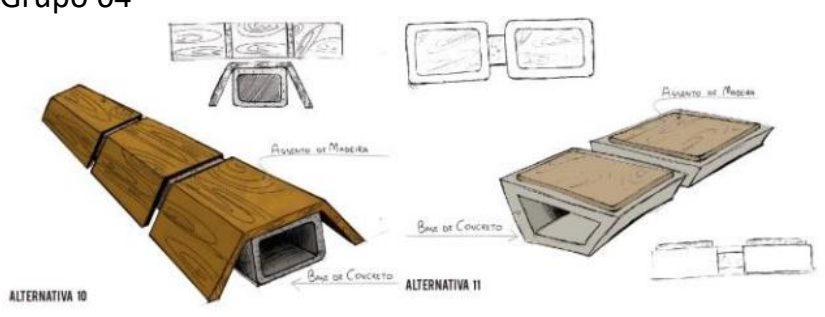

Fonte: Autores

- Grupo 05 - Espaço Urbano: Mobiliários voltados para uma maior quantidade de usuários e para grandes espaços públicos, sendo o no 12 e 13 respectivamente com área "vazada" para guardar objetos e área natural e formato geométrico; já o nำ14 possui encosto e áreas individuais para os usuários, assim como conceito geométrico e estética.

Figura 16 - Grupo 5
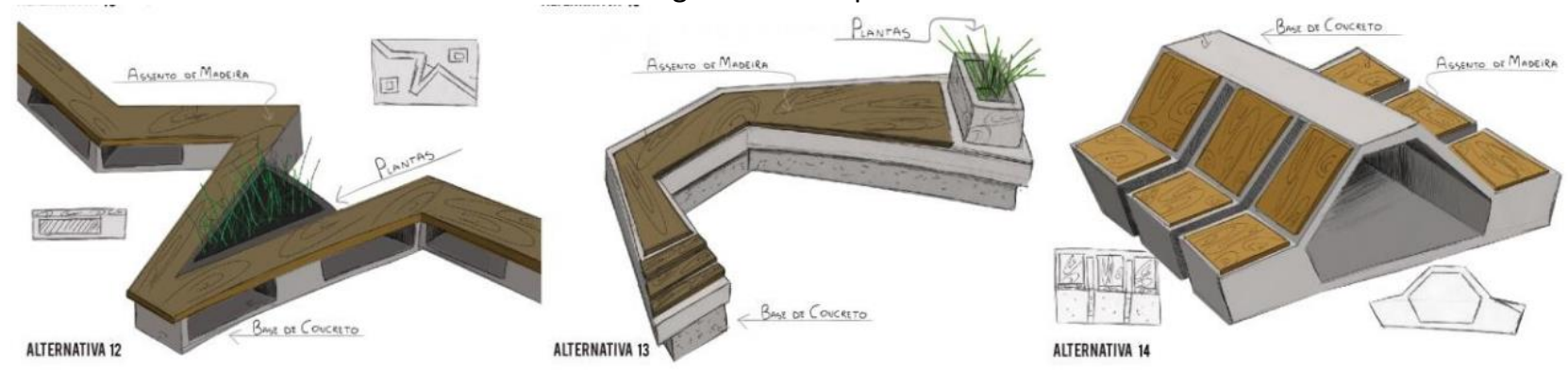

Fonte: Autores

13ㅇ Congresso Brasileiro de Pesquisa e Desenvolvimento em Design, Univille, Joinville (SC)

05 a 08 de novembro de 2018 
- Grupo 06 - Simplicidade e Geometria: Composto por 4 alternativas, sendo que a primeira utiliza formas geométricas e sinuosas, possuindo encosto para as pernas ou assento auxiliar para os usuários; a segunda explora uma forma atrativa e possui local para guardar objetos; já o concept $\mathrm{n}$-17 busca a mistura de materiais, assim como divide sua área e explora formas geométricas esteticamente atrativas; e por fim o no18 possui variação em seu assento, sendo visualmente atrativo.

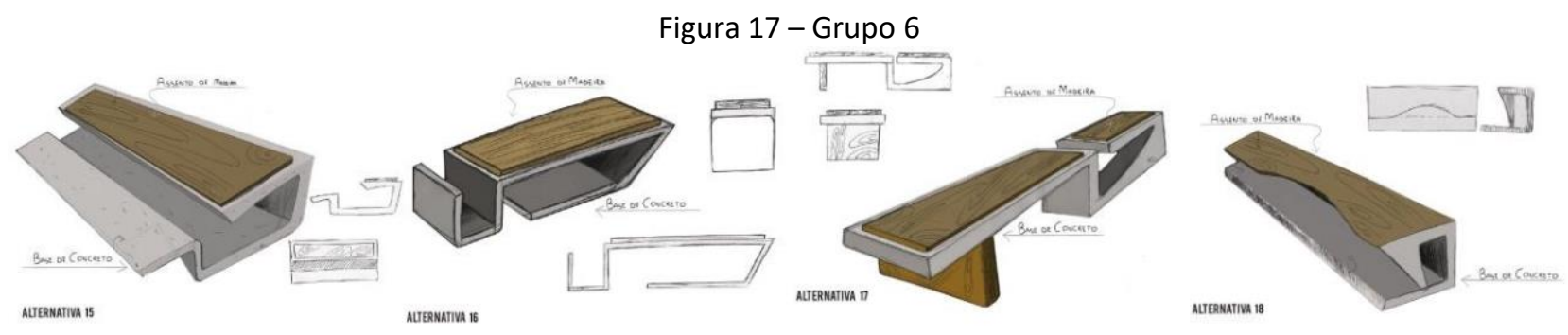

Fonte: Autores

\section{Conclusão}

Uma vez estabelecido o objetivo de gerar mobiliários urbanos amazônicos com formas e símbolos culturais, o projeto desenvolveu 18 concepts finais que utilizam a diversidade das formas geométricas e sinuosas que utilizassem concreto e madeira regional como materiais empregados na constituição dos mobiliários; dessa forma foi possível desenvolver produtos diferenciados e capazes de se relacionarem com os usuários, ao se explorar as formas em sua concepção, uma vez em que não apenas sua estética mais consequentemente sua função gera um apelo ao indivíduo na utilização de tal.

Através desta pesquisa houve a compreensão que na projetação de mobiliários, é necessário levar em conta a interação deste com o usuário buscando estabelecer um vínculo que desperte a sensação de agrado, satisfação e apego ao utilizar e observar o mobiliário.

Com o auxílio da fase de testes foi possível demonstrar a diferença da aplicação do design emocional a partir da comparação dos resultados iniciais para os dos concepts finais propostos, exemplificando assim que o desenvolvimento de produtos interativos a partir de conceitos locais, eleva a curiosidade e interesse do usuário e beneficia o ambiente criando harmonia e inovação.

O projeto possibilitou a explanação de como a dinâmica produto-usuário funciona, além de demonstrar que quando aplicado o Design Emocional, os produtos desenvolvidos cumprem suas funções estéticas e funcionais de forma mais eficiente. Desta forma é possível entender que o estudo sobre o design de produto interativo contribui para a concepção de artefatos relevantes e atuantes no meio, ou ao usuário com o qual estarão relacionados.

Por fim a pesquisa foi capaz de apreciar a interação: homem-produto-sociedade na geração de novos mobiliários conceituais, trazendo inovação para o desenvolvimento de produtos culturais dentro do Design a partir do uso de técnicas e ferramentas voltadas para o usuário. 


\section{Referências}

BAXTER, M. Projeto de Produto. 3. ed. São Paulo: Blucher, 2011.

BONSIEPE, G. A Tecnologia da Tecnologia. São Paulo: Ed. Blücher, 1983.

CAICEDO, David Güiza, DESMET, P. M. A. Designing the new PrEmo An empirical research on how to improve the emotion measuring tool. Delft University of Technology, Holanda, 2009.

DESMET, Pieter M. A. Designing Emotions. Delft University of Technology, 2002

GOMES, Luiz A. V. Negreiros. Criatividade: Projeto, desenho, produto. 3a Ed. Santa Maria, RS:Schds, 2004.

HEKKERT, P. Design aesthetics: Principles of pleasure in product design. Psychology Science, 2006. LOBACH, B. Design Industrial; bases para configuração dos produtos industriais. Edgard Blucher. São Paulo, 2001.

TONETTO, L. M. E XAVIER DA COSTA, F. C. Design emocional: conceitos, abordagens e perspectivas de pesquisa. Strategic Design Research Journal, 2011.

MUNARI, Bruno. Das coisas nascem coisas. 2a Edição, São Paulo - Ed. Martins Fontes, p.96, 2008. NORMAN, Donald A. Why we love (or hate) Everyday Things. Nova York, Estados Unidos, Basic Books, 2004.

PENTEADO, Ana Carolina Bonini \& RIBEIRO, Rosamelia Parizotto. Ferramentas para a avaliação de design emocional em projetos de design. 2016.

PICHLER R. F.\& MELLO C. I. O Design e a Valorização da Identidade Local. 2013.

WHEELER, Alina. Design de Identidade de Marca. 2aㅡ Ed. Porto Alegre: Bookman, 2008. 